\title{
Evaluatie van het landelijk project Integratie van sekse in het medisch basiscurriculum
}

\author{
P. Verdonk • T. Lagro-Janssen
}

Samenvatting Inleiding: In 2002 startte een landelijk project om sekse te integreren in alle medische basiscurricula. In dit artikel gaan we in op de volgende vragen: welke stappen zijn genomen in het project, welke factoren speelden een gunstige rol, en hoe is het project ontvangen?

Aanpak en resultaten: Het project ging van start met de evaluatie van een Nijmeegs pilotproject, gevolgd door de inrichting van een Kenniscentrum Seksespecifiek Medisch Onderwijs. Vervolgens zijn van zeven medische faculteiten de studiegidsen gescreend op aan- of afwezigheid van aandacht voor sekse in het onderwijs. De resultaten van deze screening zijn besproken met beleidsmakers en onderwijsdirecteuren en in alle faculteiten is het onderwijsmateriaal van praktische aanbevelingen voorzien. Tot slot is aan de hand van interviews het project geëvalueerd met trekkers en onderwijsdirecteuren. Factoren die het implementatieproces bij de faculteiten gunstig (kunnen) beïnvloeden zijn onder andere: openlijke ondersteuning, consensus op beleidsniveau, organisatie van het onderwijs en een open houding van onderwijscoördinatoren. De gedachte dat medische kennis neutraal en objectief is leeft sterk; ook heerst de mening dat cultuurverschillen relevanter zijn dan sekseverschillen. Over sociale verantwoordelijkheid en (on)gelijkheid werd door beleidsmakers en

\footnotetext{
P. Verdonk $(\bowtie)$

Mw dr. P. Verdonk is psycholoog/universitair docent Arbeid en Gezondheid, Universiteit Maastricht; ten tijde van het project was zij werkzaam in het UMC St Radboud bij Vrouwenstudies Medische Wetenschappen.

Correspondentieadres:Mw. dr. Petra Verdonk, Universiteit Maastricht, faculteit HML, afd. Sociale Geneeskunde, postbus 616, 6200 MD Maastricht; tel.: 043-3881713; email: p.

verdonk@beoz.unimaas.nlBelangenconflict: geen gemeld.

Financiële ondersteuning: geen gemeld.
}

onderwijsdirecteuren nauwelijks iets opgemerkt. Uit de nadruk die gelegd werd op het belang van zorgvuldige communicatie blijkt dat het project sterk politiek geladen was.

Discussie en conclusies: In de medische faculteiten is integratie van sekse meer bespreekbaar geworden; het project heeft tot concrete aanpassingen in het onderwijs geleid. Bestaande weerstand tegen het project heeft zowel te maken met de opvatting dat medische kennis sekseneutraal is als met de ontkenning van het bestaan van een hiërarchie tussen de seksen.

\section{Inleiding}

Gezondheidsverschillen tussen de seksen hangen samen met biologische, psychische, sociale, culturele en maatschappelijke factoren. Niet alleen bij de reproductie, maar ook bij andere aandoeningen doet sekse er toe, bijvoorbeeld als het gaat om risicofactoren, medische consumptie, klachtpresentatie, de gevolgen van ziekte en de behandeling en bejegening door de hulpverlener. ${ }^{1}$ Aandacht voor sekse draagt zowel bij aan een betere gezondheid van mannen en vrouwen als aan een betere gezondheidszorg omdat mannen en vrouwen de zorg krijgen die ze nodig hebben. Door aandacht te besteden aan verschillen kan ongelijkheid worden verminderd; zo zullen bij vrouwen hart- en vaatziekten beter herkend worden, en bij mannen depressies. Daar dokters onvoldoende afweten van de betekenis van sekse voor gezondheid en ziekte is de integratie van sekse in het medisch onderwijs zo belangrijk. Immers, daar wordt de dokter van de toekomst opgeleid. 
De toegenomen kennis over sekseverschillen in gezondheid en ziekte drong onvoldoende door tot de medische praktijk en de medische opleidingen. Om dit te veranderen stelde minister Borst in 1996 de Stuurgroep Vrouwenhulpverlening in. De Stuurgroep rapporteerde in 1999 het volgende over de medische opleidingen: er was slechts op een paar faculteiten, en dan nog wisselend in kwantiteit en kwaliteit, aandacht voor sekse in het curriculum; er was geen sprake van structurele inbedding binnen het curriculum; nergens bestond een samenhangend seksespecifiek onderwijsprogramma en docenten hadden onvoldoende tijd voor en kennis van seksespecifieke onderwerpen. ${ }^{2}$ De aanbevelingen van de stuurgroep richtten zich op de herziening van de eindtermen voor de artsopleiding: seksespecifieke elementen moesten worden opgenomen, en ook moesten studenten geneeskunde daadwerkelijk onderwijs krijgen over seksespecifieke aspecten van ziekte en gezondheid. In een inventariserend onderzoek in 2001 naar activiteiten op het gebied van interculturalisatie van het medisch onderwijs kwam men tot vergelijkbare conclusies. ${ }^{3}$ De aanwezigheid van gezaghebbende voortrekkers, zoals hoogleraren in het UMC St Radboud of het VUmc, bleek een gunstige voorwaarde voor integratie van zowel sekse als cultuur.

In 1998 startte Vrouwenstudies Medische Wetenschappen met een pilotproject in het UMC St Radboud. Een inhoudelijke analyse van het lokale basiscurriculum, gericht op het opsporen van lacunes en seksestereotypen, leverde verschillende conclusies op. ${ }^{4-5}$ Stereotypen bleken inderdaad aanwezig: vrouwen werden bijvoorbeeld vaker als 'lastige patiënt' uitgebeeld en hen werd vaker een 'baantje' in plaats van werk toegeschreven. De belangrijkste uitkomst was echter dat evidente en relevante sekseverschillen in gezondheid en ziekte, zoals bijvoorbeeld bij buikpijn, urineweginfecties, hart- en vaatziekten en farmacotherapie, genegeerd werden. Concrete aanbevelingen ter verbetering zijn besproken met de betreffende blokcoördinatoren en achtergrondliteratuur, alsmede ideeën voor toetsvragen werden aangereikt. ${ }^{6}$

In 2001 werden de eindtermen van de artsopleiding in het Raamplan aangepast. ${ }^{7}$ ZonMW (Zorgonderzoek Nederland Medische Wetenschappen) ontwikkelde een programma 'seksespecifieke zorg en preventie' waarin onder andere implementatie werd opgenomen. ${ }^{8}$ De ervaring met het pilotproject leidde tot de financiering van een bij Vrouwenstudies Medische Wetenschappen van het UMC St Radboud ondergebracht landelijk project om sekse te integreren in het medisch onderwijs. In april 2002 ging dit project van start. ${ }^{9}$ Doel was het integreren van sekse in de medische basiscurricula en te komen tot een samenhangend geheel van seksespecifiek medisch onderwijs in alle acht medische faculteiten in Nederland. Tevens was het project gericht op het scheppen van voorwaarden voor blijvende inbedding in de toekomst. In dit artikel gaan we dieper in op de volgende vragen:

1. welke stappen zijn genomen om een seksespecifiek onderwijsprogramma te bewerkstelligen in alle acht medische faculteiten in Nederland;

2. welke factoren speelden een gunstige rol bij de implementatie, en

3. hoe is het project in de faculteiten op beleidsniveau ontvangen?

\section{Stappen in het project}

Het project is gestart met de evaluatie van het Nijmeegse pilotproject, gevolgd door de inrichting van een digitaal kenniscentrum. Daarna zijn de studiegidsen van alle andere faculteiten gescreend op aan- of afwezigheid van aandacht voor sekse in het onderwijs. De resultaten hiervan zijn besproken met beleidsmakers en onderwijsdirecteuren. Vervolgens is het onderwijsmateriaal van alle faculteiten van praktische aanbevelingen voorzien. Tot slot is via interviews het project geëvalueerd met trekkers en onderwijsdirecteuren. Deze stappen worden achtereenvolgens besproken.

\section{Stap 1}

Allereerst is een seksespecifiek medisch curriculum gedefinieerd op basis van internationale literatuur en een expertisegroep (tabel 1).

Vervolgens is onderzocht in hoeverre in Nijmegen de aanbevelingen uit het Nijmeegse pilotproject waren opgevolgd, of was voldaan aan genoemde criteria van een seksespecifiek curriculum, en welke factoren bij de integratie van sekse een rol hadden gespeeld. ${ }^{10}$ Onderwijsmateriaal is opnieuw bekeken en er zijn interviews gehouden met de blokcoördinatoren.

De evaluatie leverde op dat de meerderheid van de aanbevelingen was overgenomen en dat, hoewel nog niet op alle fronten sprake was van een seksespecifiek curriculum, sinds de start van het project de verschillen tussen mannen en vrouwen wel veel meer onder de aandacht van studenten werden gebracht.

Om commitment en legitimiteit aan het project te verlenen, en voor de noodzakelijke feedback op de gehanteerde strategie en methoden, is bij de start van het project een klankbordgroep samengesteld uit diverse betrokken beleidsmakers.

\section{Stap 2}

In de tweede stap is een Kenniscentrum Seksespecifiek Medisch Onderwijs ingericht (www.kenniscentrumsdmo. 
Tabel 1 Kenmerken van een geslaagde integratie van sekse in het medisch basiscurriculum.

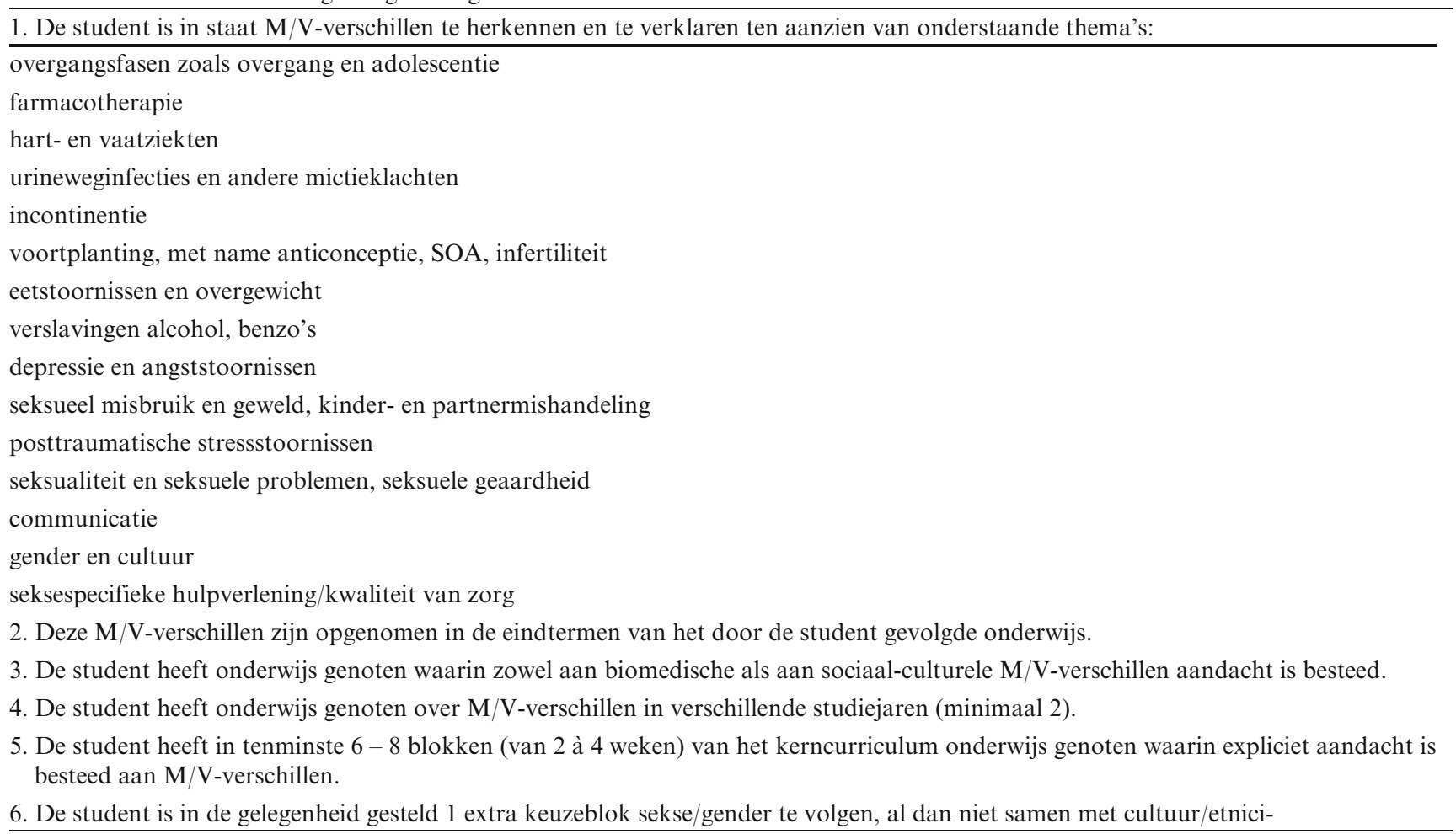

$n l)$. Hier wordt seksespecifieke kennis vertaald naar concrete medische onderwijsdoelen, en worden onderwijsmodules en seksespecifieke toets- en beoordelingsprocedures over sekseverschillen in ziekte en gezondheid ontwikkeld en docentcursussen georganiseerd. ${ }^{11}$ Tijdens de looptijd van het project hadden alle docenten van alle acht medische faculteiten via een password toegang tot het onderwijsmateriaal en konden daar werkgroepopdrachten, zelfstudieopdrachten en presentaties downloaden. Ook videomateriaal was beschikbaar. $\mathrm{Na}$ beëindiging van het project is in 2006 overgegaan tot een abonnementensysteem waarop de medische faculteiten en vervolgopleidingen zich kunnen abonneren.

Bovendien dient het Kenniscentrum als centrum voor inventarisatie, documentatie en consultatie. In 2004 en 2005 zijn tijdens de looptijd van het project twee Invitational Conferences georganiseerd alsmede een docentcursus. Gelijktijdig met de ontwikkeling en inrichting van het kenniscentrum is gestreefd naar de opname van een aanvullende vraag in de visitatieronde in 2003. En met succes. De Visitatiecommissie stelde niet alleen vragen over de mate waarin sekse in de medische curricula was geïmplementeerd, maar ook over de verdeling van mannen en vrouwen over de functieniveaus. Hoewel de antwoorden op de vraag naar de integratie van sekse in het curriculum niet zijn opgenomen in het eindrapport van de Visitatiecommissie en de leden van de commissie zich niet bewust waren van deze omissie, gaven alle faculteiten inzage in hun antwoord op de aanvullende vraag. Hierin bevestigden zij hun deelname aan het project Integratie van Sekse.

\section{Stap 3}

Vervolgens is een quick-scan ontwikkeld om in de studiegidsen, waarin de faculteiten hun onderwijsprogramma samenvatten, de aan- of afwezigheid van aandacht voor sekse in het onderwijs te screenen. Deze screening van de studiegidsen van alle andere medische faculteiten bood niet alleen een overzicht van lacunes maar ook van mogelijkheden om sekse alsnog in te voegen. Zoals verwacht bleek er nauwelijks aandacht te zijn voor sekse in het onderwijs, met uitzondering van de voortplanting. ${ }^{12}$ De screeningsverslagen, met lacunes en mogelijkheden om sekse te integreren, zijn besproken met onderwijsdirecteuren en beleidsmakers van alle faculteiten. Deze stap werd als succesvol beschouwd indien er consensus bestond over de afwezigheid van sekseverschillen in het onderwijs en over de noodzaak tot implementatie, gekoppeld aan afspraken over de implementatiestrategie. Alle faculteiten zegden hun deelname aan het project toe en deze stap werd bezegeld met een schriftelijke steunbetuiging van de decaan. Onderwijsmateriaal van alle faculteiten werd ter screening meegegeven en overal zijn afspraken gemaakt over de werkwijze. 
Stap 4

In stap vier is het onderwijsmateriaal van alle medische faculteiten, zoals blokboeken en patiëntencasus, gescreend op inhoud (welke thema's zijn wel en welke zijn niet in het onderwijs opgenomen), context (in welke context worden patiënten gepresenteerd) en taal (wordt wel of niet op stereotype wijze over patiënten, studenten en docenten gesproken). ${ }^{4}$ De in de screeningsverslagen opgenomen aanbevelingen om sekse te integreren in het desbetreffende onderwijsblok zijn besproken met de onderwijscoördinatoren. Van alle gesprekken zijn verslagen gemaakt en deze zijn ter accordering voorgelegd.

\section{Stap 5}

In de laatste stap is het project aan de hand van een interviewgids geëvalueerd met onderwijsdirecteuren, beleidsmakers en trekkers op de faculteiten. Daarnaast zijn per faculteit minimaal twee personen telefonisch geïnterviewd over hun opvattingen ten aanzien van het project. De interviews boden tegelijkertijd de mogelijkheid voor het bespreken van toekomstplannen ten aanzien van de integratie van sekse, zoals bijvoorbeeld de noodzaak tot aandacht voor sekse in het onderwijsbeleid.

\section{Factoren die gunstig zijn voor het implementatieproces}

Gunstige factoren bij de implementatie zijn zowel aspecten van de projectstrategie als kenmerken van de faculteiten. Uit de evaluatie van het Nijmeegse pilotproject kwam bijvoorbeeld het belang naar voren van concrete aanbevelingen die goed aansluiten bij bestaand onderwijsmateriaal, en duidelijk relevant zijn voor de dagelijkse, medische praktijk. Praktische ondersteuning in de vorm van onderwijsmateriaal spaart tijd uit en draagt bij aan begrip van de relevantie van sekse, des te meer indien de onderwijscoördinator sekseverschillen waarneemt in de eigen praktijk als arts. De betrokkenheid van coördinatoren bij de besluitvorming speelt een rol, evenals de aanwezigheid van een deskundige trekker in de faculteit. ${ }^{10}$ Met deze factoren is rekening gehouden in het landelijke project, onder andere door de inrichting van het Kenniscentrum.

Aan de hand van drie casestudies zijn kenmerken van de faculteiten gedestilleerd die een rol hebben gespeeld bij de integratie van sekse. ${ }^{13}$ Hieruit blijkt dat openlijke ondersteuning en consensus op beleidsniveau belangrijk zijn. Ook speelt de organisatie van het onderwijs een rol, zoals de aanwezigheid van duidelijke procedures voor curriculumontwikkeling en -evaluatie, een probleemgestuurd curriculum, en een goede communicatie- infrastructuur in het onderwijs. Ook een open houding van onderwijscoördinatoren ten aanzien van (deze) verandering is gunstig voor een soepele inbedding. De trekker moet een invloedrijke en zichtbare positie binnen de faculteit bezetten, waarin vele formele en informele contactmomenten plaatsvinden met onderwijscoördinatoren, om seksespecifieke thema's onder de aandacht te kunnen brengen. Bovendien zijn de communicatieve vaardigheden van de trekker van grote waarde. Genoemde factoren beïnvloeden elkaar wederzijds. Openlijke steun van de onderwijsdirecteur draagt bijvoorbeeld bij aan enthousiasme van de trekker en vergroot diens mogelijkheden om tijd te besteden aan het project. Vrouwen vinden het project van groter belang, maar zij bevinden zich op minder invloedrijke en minder zichtbare posities. Derhalve speelt de seksesegregatie in de medische faculteiten een ongunstige rol bij de integratie van sekse.

\section{Ontvangst van het project in de medische faculteiten}

Uitgangspunten van het project waren de volgende: sekseverschillen in gezondheid en ziekte komen onvoldoende aan bod in het medisch onderwijs, kennis over sekseverschillen is relevant voor de medische praktijk, en deze kennis draagt zowel bij aan kwaliteit van zorg als aan een grotere gelijkheid tussen mannen en vrouwen. De interviews met onderwijsdirecteuren, lokale trekkers, en beleidsmakers uit de laatste stap zijn telefonisch afgenomen, op band opgenomen en uitgeschreven. ${ }^{13} \mathrm{Er}$ is gevraagd in hoeverre de uitgangspunten van het project aansluiten bij gangbare opvattingen binnen de medische faculteit. Uit de analyse van de interviews kwamen vier thema's naar voren.

Het eerste thema, namelijk de gedachte dat geneeskundige kennis uit neutrale kennis bestaat, beïnvloedde niet zozeer de vraag óf, maar wel wélke sekseverschillen in het onderwijs konden worden opgenomen. Met name biomedische sekseverschillen die niet conflicteren met de gedachte dat kennis objectief en neutraal is passen binnen dit thema.

In het tweede thema relevantie-van-sekse bleek niet alleen het belang van aandacht voor sekseverschillen in gezondheid en ziekte, maar ook het relatieve belang van sekse ten opzichte van andere sociale categorieën ter discussie te staan. Diversiteit, en dan met name etniciteit/cultuur, speelt hierin een prominente rol. De algemeen heersende gedachte is dat cultuur/etniciteit belangrijker is dan sekse, omdat culturele verschillen 'echte' verschillen zijn en 'meer relevant' voor de medische praktijk. De geïnterviewden gaven aan dat de koppeling tussen sekse en cultuur/etniciteit minder 
weerstand had opgeroepen. Echter, de vraag is gerechtvaardigd of deze nadruk op cultuur/ etniciteit niet voortkomt uit weerstand tegen aandacht voor sekse. Met uitzondering van Utrecht is nergens gelijktijdig met de integratie van sekse aandacht gevraagd voor culturele verschillen. Bovendien bleek van een uitwerking van het begrip diversiteit, inclusief ongelijkheid tussen etnische of cultureel van elkaar verschillende groepen, geen sprake.

Een derde thema, namelijk sociale verantwoordelijkheid, werd dan ook nauwelijks genoemd. Medische opleidingen hebben de sociale verantwoordelijkheid om hun middelen te richten op belangrijke gezondheidsproblemen waaronder gezondheids- en welvaartsverschillen. ${ }^{14-15}$ Aan het begrip sociale verantwoordelijkheid liggen vier waarden ten grondslag: kwaliteit, sociale gelijkheid, kosten-effectiviteit en relevantie voor de dagelijkse medische praktijk. Echter, de sociale verantwoordelijkheid van medische opleidingen met name ten aanzien van maatschappelijke ongelijkheid werd nauwelijks genoemd. Aandacht voor sekseongelijkheid in het project wekte eerder achterdocht, omdat er in dat geval wellicht sprake was van een politieke, en derhalve, meende men, nietwetenschappelijke agenda.

Symbolisch voor de politieke beladenheid van het project was de nadruk op het derde thema zorgvuldige communicatie. Zorgvuldige communicatie, zo blijkt uit de interviews, bestaat uit vasthoudendheid zonder drammerig te worden. Door communicatief vaardig te opereren kregen we toestemming onderwijsmateriaal van aanbevelingen te voorzien en deze te bespreken met onderwijscoördinatoren. Maar tegelijkertijd werden sommige thema's, zoals partnergeweld of seksueel misbruik, hierdoor moeilijk bespreekbaar.

\section{Discussie en conclusies}

Voor een systematische evaluatie van de mate waarin de aanbevelingen daadwerkelijk geïntegreerd zijn ontbreken vooralsnog de middelen. Hoopvol is wel dat inmiddels één van de faculteiten in de onderwijsevaluaties is gestart met het daadwerkelijk monitoren van seksespecifieke aspecten in het onderwijs. Ook zou een nieuwe quick-scan van de studiegidsen inzicht kunnen verschaffen. Desondanks is onze conclusie dat het project de betekenis van sekse voor ziekte en gezondheid in de medische faculteiten veel meer bespreekbaar heeft gemaakt. Dit blijkt onder andere uit de opname van concrete aanbevelingen in onderwijsprogramma's, uit de aanpassing van leerdoelen, de integratie van sekse in het onderwijsbeleid van verschillende faculteiten, en uit de ontwikkeling van het keuzeonderwijs.
Sekse kan succesvol geïmplementeerd worden in het medisch onderwijs. Hiervoor zijn wel een aantal voorwaarden noodzakelijk. Het belang van positieve factoren, zoals concrete en direct toepasbare aanbevelingen, praktische ondersteuning en de motivatie bij docenten, bevestigen de bevindingen van andere auteurs. ${ }^{4,16}$ De kenmerken van de faculteiten die een positieve rol spelen zijn eveneens in eerdere studies genoemd, zoals een open houding in de faculteit of een probleemgestuurd curriculum. ${ }^{17-18}$

Ondanks de bestaande lacunes over de betekenis van sekse voor gezondheid en ziekte, werd een sekseperspectief in de geneeskunde veelal gezien als een feministische opvatting, terwijl biomedische kennis gezien werd als objectieve en neutrale kennis. In de geneeskunde is het niet gebruikelijk om medische kennis vanuit een specifiek gezichtspunt te beschouwen. Echter, door velen is inmiddels beargumenteerd dat de claim 'dat medische kennis neutraal is en universeel geldig voor alle patiënten' niet valide is. ${ }^{19-20}$ De nadruk op aandacht voor diversiteit, in concreto cultuur/etniciteit, speelde een bijzondere rol bij de implementatie, waarbij men stelde dat een nadruk op sekse weerstand opriep die moest worden vermeden. Naar onze mening was het verleggen van het accent naar cultuur/etniciteit eerder een uiting van de vooronderstelling dat sekse/gender niet zo belangrijk is. Culturele verschillen werden als 'echt' en 'relevant' gezien. Desalniettemin werd nauwelijks uitgewerkt wat precies werd bedoeld met 'diversiteit'; van integratie in het onderwijs van andere aspecten van diversiteit zoals seksuele oriëntatie, leeftijd of sociaaleconomische status was geen sprake, en ook werden culturele verschillen niet gezien als zaken waar ongelijkheid een rol in speelde. Symbolisch voor de gevoeligheid van het onderwerp was de nadruk op een zorgvuldige communicatie.

De laatste jaren heeft een enorme toename in kennis plaatsgevonden over sekseverschillen in gezondheid en ziekte alsmede in specifieke vrouwen- én specifieke mannengezondheidsproblemen. Deze toegenomen kennis maakte het voor de faculteiten eenvoudiger om concrete onderwerpen in hun onderwijs in te vlechten. Bovendien staan vrouwen- en mannengezondheidsproblemen centraal, zodat sekse/gender minder als ongewenste feministische inmenging wordt afgedaan. Maar daarmee wordt wel ten onrechte de sociale verantwoordelijkheid ten aanzien van (on)gelijkheid veronachtzaamd. Risberg en collega's stellen dat de weerstand tegen aandacht voor sekse in medische opleidingen mede voortkomt uit de ontkenning van het bestaan van een hiërarchie tussen de seksen. ${ }^{21}$ Ook in onze studie kwam deze ontkenning naar voren, ondanks de duidelijk aanwezige hiërarchie in de medische opleidingen. Een situatie met vrouwen op minder invloedrijke en minder zichtbare posities draagt 
namelijk bij aan het voortbestaan van de opvatting dat sekse minder belangrijk of minder relevant wordt geacht voor de medische praktijk. Vrouwen zijn zich meer dan mannen bewust van deze hiërarchie tussen de seksen en zij zien ook meer de relevantie van sekse/gender voor een gelijkwaardige geneeskundige praktijk.

Veranderen roept altijd weerstand op. In het specifieke geval van sekse/gender heeft deze weerstand veel te maken met de opvatting dat medische kennis sekseneutraal is, én met de ontkenning van het bestaan van een hiërarchie tussen de seksen, ook op de medische faculteiten.

\section{Summary}

Introduction: In 2002 a national project was launched aimed at incorporating gender into Dutch undergraduate medical education. This article addresses the questions: which steps have been taken, which key factors played a role, and how was the project received? Strategy: A pilot project at Radboud University Nijmegen Medical Centre was evaluated and a Knowledge Center for Gender-Specific Medical Education set up. Next, syllabuses of medical curricula were examined to determine whether attention was paid to gender issues or not. The results of these activities were discussed with policy makers and education directors. Practical recommendations regarding gender issues were integrated into course material. Change agents and education directors were interviewed to evaluate the project. Clear backing from education directors and consensus among policy makers, curriculum organisation, and an open attitude of course organisers promoted incorporation of gender-related issues into medical curricula. The prevailing idea was that medical knowledge is objective and neutral and ethnic/cultural differences were regarded as more important than gender-related differences. Policy makers and education directors said little about medical schools' social responsibility and (in) equality issues. That the project was politically highly sensitive was reflected by the emphasis on careful communication. Discussion and conclusions: The project has enabled more open discussion of sex/gender issues in the medical faculties and has resulted in educational changes. Resistance to the project stems from the view that medical knowledge is gender neutral and from denial of a genderrelated hierarchy. (Verdonk P, Lagro-Janssen T. Evaluation of the national project on Integrating Gender in Undergraduate Medical Education. Dutch Journal of Medical Education 2007;26(5): 228236).

\section{Literatuur}

Lagro-Janssen T, Noordenbos G. Sekseverschillen in ziekte en gezondheid. Nijmegen: SUN; 1997.

Stuurgroep Vrouwenhulpverlening Ministerie van VWS. Naar een seksespecifieke en multiculturele gezondheidszorg in de 21 ste eeuw. Eindrapportage en beleidsaanbevelingen. Den Haag: Ministerie VWS; 1999.

Wieringen JCM van, Kylstra MA, Schulpen TWJ. Interculturalisatie van het medisch onderwijs in Nederland. Een inventarisatie bij de faculteiten geneeskunde. Den Haag: SGO; 2001.

Zelek B, Phillips SP, Lefebvre Y. Gender sensitivity in medical curricula. Can Med Assoc J 1997; 156(9):1297-1300.

Sanden J van der, Lagro-Janssen T. Aandacht voor sekseverschillen ontbreekt in artsenopleiding. Med Contact 1999;54:11958.

Sanden J van der, Frijns T, Lagro-Janssen T. Seksespecifieke geneeskunde in het medisch onderwijscurriculum. Projectverslag. Nijmegen: KUN, Faculteit der Medische Wetenschappen; 1999.

Metz JCM, Verbeek-Weel AMM, Huisjes HJ. Raamplan 2001 Artsopleiding. Bijgestelde eindtermen van de artsopleiding. Nijmegen: Mediagroep; 2001.

SZW 0000755. Derde CEDAW-rapportage inzake de uitvoering van het VN-vrouwenverdrag in Nederland. Den Haag; 7 september 2000 .

Lagro-Janssen T. De integratie van de factor sekse binnen het basiscurriculum geneeskunde. TSG 2002;80(4):269-271.

Verdonk P, Mans LJL, Lagro-Janssen ALM. Integrating gender in a basic medical curriculum. Med Educ 2005;39:1118-1125.

Mans LJL, Verdonk P, Lagro-Janssen ALM. De rol van het Digitaal Kenniscentrum Seksespecifiek Medisch Onderwijs bij de integratie van sekse in het medisch onderwijs. Tijdschrift voor Medisch Onderwijs 2006;25(2):66-74.

Verdonk P, Mans LJL, Lagro-Janssen ALM. How is gender integrated in the curricula of Dutch medical schools? A quick-scan on gender issues as an instrument for change. Gender Educ 2006:18(4):399-412.

Verdonk P. Gender matters in medical education. Integrating a gender perspective in medical curricula [dissertatie]. Nijmegen: UMC St Radboud; 2007.

Woollard RF. Caring for a common future: medical schools' social accountability. Med Educ 2006;40:301-313.

Boelen C. The five-star doctor: An asset to health care reform? Human Resources for Health Development Journal 1997;1 (1):6-12. Beschikbaar op: www.who.int/hrh/en/ HRDJ_1_1_02.pdf (accessed 20 April 2006).

Searle J. Introduction of a new curriculum in women's health in medical education: a framework for change. Womens Health Issues 1998;8(6):382-88.

Henrich JB. Women's Health Education Initiatives: Why Have They Stalled? Acad Med 2004;79(4):283-8.

Levison SP, Straumanis J. FIPSE: changing medical education forever - Fund for the Improvement of Postsecondary Education. Change Magazine 2002;34(5):18-27.

Beagan B. Neutralizing differences: producing neutral doctors for (almost) neutral patients. Soc Science Med 2000;51(8):125365.

Lagro-Janssen T. De tweeslachtigheid van het verschil [inaugurele rede]. Nijmegen: SUN; 1997.

Risberg G; Hamberg K; Johansson EE. Gender awareness among physicians - the effect of specialty and gender. A study of teachers at a Swedish medical school. BMC Med Educ $2003 ; 3: 8$. 